Article

\title{
Spaces of Urban Citizenship: Two European Examples from Milan and Rotterdam
}

\author{
Alba Angelucci \\ DESP-Department of Economics, Society, and Politics, University of Urbino Carlo Bo, 61029 Urbino, Italy; \\ E-Mail: alba.angelucci@uniurb.it
}

Submitted: 7 July 2019 | Accepted: 8 August 2019 | Published: 28 November 2019

\begin{abstract}
This article aims to highlight the emergence of urban citizenship spaces in two European cities-Milan, Italy, and Rotterdam, the Netherlands-where marginality and social exclusion are faced and coped with through social participation, appropriation of space, and the construction of a peculiar place-based sense of belonging. To do so, the article will present the results of comparative research conducted in Milan and Rotterdam by means of 60 semi-structured interviews ( 30 in each city) with inhabitants of peculiar neighbourhoods in the two cities. The analysis will adopt an intersectional perspective (Crenshaw, 1989), paying attention to the intersection between personal characteristics and spatial features to highlight the processes occurring at the crossroads between the social and spatial categories. In particular, this work will present two examples, one from each city involved in the research, in which urban citizenship practices are enacted and create a Lefebvrian space of representation where dominant discourses and narratives are overcome and overturned by people otherwise excluded from dominant spaces and mainstream forms of urban citizenship. A comparison of the fieldwork from the two cities shows how in both cases, subaltern and/or marginalised groups (women, the poor, and migrants in particular) manage to appropriate interstitial spaces within the city where they can find room for expression and well-being and for the performance of urban citizenship practices. At the same time, though, external (political and economic) factors can transform those spaces of representation into self-constraining places which can expose these marginal groups to further vulnerability.
\end{abstract}

\section{Keywords}

intersectionality; representation; right to the city; urban citizenship; urban spaces

\section{Issue}

This article is part of the issue "Inclusion through Enacted Citizenship in Urban Spaces" edited by Rachel Kurian (Erasmus University Rotterdam, The Netherlands) and Helen Hintjens (Erasmus University Rotterdam, The Netherlands)

(C) 2019 by the author; licensee Cogitatio (Lisbon, Portugal). This article is licensed under a Creative Commons Attribution 4.0 International License (CC BY).

\section{Introduction: A Spatialized Urban Citizenship and the Right to the City}

The analysis presented in this article relies on a specific understanding of urban citizenship which connects it to the Lefebvrian concept of the right to the city (Lefebvre, 1968) and to Lefebvre's spatial theory (Harvey, 2008; Purcell, 2003).

At the basis of Lefebvrian spatial theory is the assumption that space is a social product made of power relations lying on the productive system. These express themselves through a spatial triad comprised of the spatial practice, the representation of space, and the space of representation (Lefebvre, 1974). The first dimension constitutes the context of social relations, and it can be assimilated with the actual space that people meet in their daily life. The second dimension constitutes the conceptual framework which imposes itself mostly through the work of intellectuals and artists who sustain dominant and prevalent narratives and conceptions about society. The third dimension, the space of representation, is the space of everyday life and is linked to the marginal segments of society. This is the space of people who struggle for the (re)appropriation of the city against the dominant intellectuals' conceptions of space.

For its part, the right to the city is linked to the active use that citizens make of urban space. In Lefebvrian terms, it is the possibility for all of the people to perform 
practices of participation in and appropriation of urban space, engendering a sense of belonging. Connecting this notion to the production of space allows one to argue that the performance of the right to the city takes place within the space of representation through citizens' spatial practice, and proposing a different (opposite, conflictual) representation of space, a new conception of it.

Lefebvre never talks explicitly about citizenship. Nonetheless, numerous scholars (Chiodelli, 2009; Purcell, 2002) have pointed out that the possibility to act and produce urban space can be assimilated with a new concept of citizenship that may be defined as urban. In this perspective, disconnecting citizenship from the nation-state level is possible, tying the fruition of rights to participation and a sense of belonging to a city rather than to a national group (Glick Schiller \& Çağlar, 2015; Lepofsky \& Fraser, 2003; Painter, 2005).

Scholars have provided different definitions of urban citizenship, always highlighting different aspects of it: its insurgent character (Holston, 2008), its political nature (Beauregard \& Bounds, 2000), and its performative dimension (Pine, 2010), to give some examples. The link to the Lefebvrian concept of the right to the city enables the present work to consider and include all of these aspects while going a step forward towards a spatialised description of it.

Indeed, urban citizenship and the right to the city share some important assumptions.

First, both of them are at the same time producers and products of urban space. Furthermore, they do not deal with the juridical and official rights conceded by an institution to people, but instead they focus on people's performances and on their ability to both symbolically and materially appropriate a city's spaces, paying attention to the everyday and subjective as constitutive elements of citizenship rights. In this sense, migrants can also significantly contribute to the redefinition of urban spaces through their urban practices, notwithstanding their juridical status (Glick Schiller \& Çağlar, 2010).

Therefore, in both conceptualizations, citizenship rights and duties are inflected on the spatial level and on an urban scale, and they are played and negotiated through the elements of participation, appropriation, and sense of belonging.

That the right to the city is one of the constitutive elements of urban citizenship (Plyushteva, 2009) is arguable, then, because it is the ability to appropriate and shape one's own environment.

Therefore, inhabitants and users can conduct, under certain conditions, slow and micro urban transformations by means of different uses of and narratives about space. This work will investigate if and how peculiar places become actual spaces of representation which can host the expression of alternative forms of urban citizenship.

As other scholars have noticed (Fenster, 2005), the Lefebvrian definition of the right to city is missing the gendered dimension of society's structure of power. In this work, this dimension will be retrieved to consider all of the aspects playing a role in processes of inclusion and exclusion as well as participation and marginalisation occurring within (and through) urban spaces.

In this work, the adoption of the analytical frame of urban citizenship is motivated by both scientific and political stakes. On the scientific side, the urban and spatialised understanding of citizenship rights and duties enables the analysis to shed light on localised and everyday dynamics impacting the inclusion and participation (as well as the exclusion and marginalisation) of different groups of people at the local level. This allows for analysis of the actual access to resources and obligations coming from the performance of citizenship practices, even when these are decoupled from an official and legal acknowledgement. For exactly this reason, from a political point of view, this perspective can inform both the policy-making process and the definition of new and more complex forms of citizenship, taking into account bottom-up, space-specific processes-the outcomes of which are anything but predictable.

\section{Research Context and Methods}

The research was conducted between 2014 and 2015 by means of 60 semi-structured interviews ( 30 in each city) with inhabitants of specific neighbourhoods in Milan and Rotterdam (throughout the article, $M$ will represent interviewees from Milan, whose quotes have been translated from the original Italian, and R interviewees from Rotterdam, whose quotes are original). The choice to compare these two cities was motivated by the fact that Milan and Rotterdam, although similar in terms of size and position within their own national contexts, present some peculiarities in terms of political and economic structure that distance each other in a significant way, precisely in relation to their approach to an (explicit or implicit) understanding of urban citizenship. Both cities are former industrial cities, important hubs, and economic centres of their respective countries; were hit hard by the economic crisis that started in 2008; and have a large share of foreign residents: $19 \%$ in Milan (Comune di Milano, 2015) and 10\% in Rotterdam (Eurostat, 2014; if considering the total portion of the population with an immigrant background in Rotterdam, the number rises to $49.1 \%)$. However, in terms of economic performance, while Milan is a sort of best practice in the Italian context, Rotterdam has one of the highest shares of unemployment in the Netherlands and is home to the most deprived areas of the country. On the political and policy levels, as clearly emerges from the literature, Milan is embedded in a weak national framework in which immigration has been treated as an emergency for too long, leaving much room for discretional, fragmented, and territorial measures and lacking an effective shared national discourse about integration (Angelucci, Marzorati, \& Barberis, 2019; Barberis, 2018; Barberis, Kazepov, \& Angelucci, 2014). In comparison, Rotterdam 
is grounded in strong and consistent national guidelines that have shifted from a multicultural and pluralist approach to an assimilationist one that shows a decrease of openness and tolerance regarding citizenship and immigration (Duyvendak \& Scholten, 2012; Koopmans, 2013). Strongly influenced by the national model of integration, Rotterdam's local policy context mirrors that assimilationist assumption even though it primarily focuses on enhancing the city's economic performance (Tersteeg, van Kempen, \& Bolt, 2013). These relevant differences embedded in similar structural conditions draw a comparison between actual practices of urban citizenship and urban space that can highlight how these may or may not influence the emergence of urban citizenship spaces.

As for Milan, the neighbourhoods considered are in the north-eastern part of the city (Figure 1), and in Rotterdam the focus was prevalently on the southern and western parts of the city (Figure 2).

To consider peculiar categories such as stigmatisation and marginality, the selected neighbourhoods mirrored specific characteristics. First, the neighbourhoods are among those generally considered the most marginal ones within the two cities; second, they are highly diversified in both cultural and socioeconomic terms. The two specific examples of representational space were selected because they reflect in a perfect way the characteristics of the neighbourhood, and they are considered by residents a sort of emblem of the neighbourhood to which they belong. The interviewees were purposefully selected to cluster two groups who were highly heterogeneous in terms of social class, occupational status, origin, age, and gender. In the first group (Milan), 15 women and 15 men were interviewed, both Italians and immigrants from nine different countries (China, Egypt, Eritrea, Japan, Peru, the Philippines, Somalia, Sri Lanka, and Tunisia), belonging to different age groups, ranging from 18 to 77 years old. Within this group were also

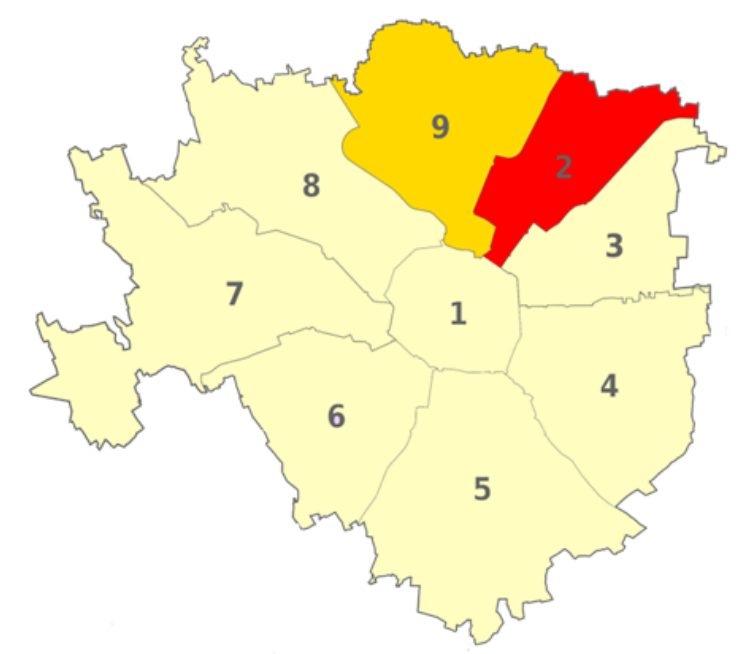

Figure 1. Milan divided into municipalities, highlighted no. 2 and no. 9. Source: Author. internal migrants (no. 7, from both rural areas of the north and poorer cities of the south of (taly) and secondgeneration migrants (no. 3). Income levels and social class varied from working to upper classes.

In the second group (Rotterdam), there were 17 women and 13 men, and the interviewees came from 14 countries (including the Netherlands). In addition to natives, the people interviewed were from the Antilles, Belgium, Colombia, France, Ghana, Iran, Italy, Norway, Romania, Saudi Arabia, Suriname, Turkey, and the United Kingdom. In this case also, different age groups were represented (from 18 to 75 years old), and both internal migrants (no. 5) and second-generation immigrants (no. 4) were included, as were different income levels and social classes. In both cases, the selection was made starting from different foci, accessed through gatekeepers, and then snowballing from the first interviewees to the following.

The data collected through the interviews were then analysed using Critical Discourse Analysis (Fairclough, 2003), which is a kind of sociolinguistic analysis characterised by its attention to societal power structures produced, maintained, and reinforced by way of language. According to this approach, analysing discourses in a critical way makes it possible to unveil power relations that structure society, connecting (social) structure and (people) agency. From this work perspective, Critical Discourse Analysis enables the analysis to keep together spatial practice (agency), representation of space (structure), and space of representation (narratives) in a circular movement from the micro to the macro and vice versa.

If Critical Discourse Analysis is the analytical tool adopted by this work, then intersectionality theory (Crenshaw, 1989) constitutes its methodological framework. Although providing an exhaustive definition of the intersectionality theory ${ }^{1}$ is not possible here, it is possible to partially describe the theory as an analytical

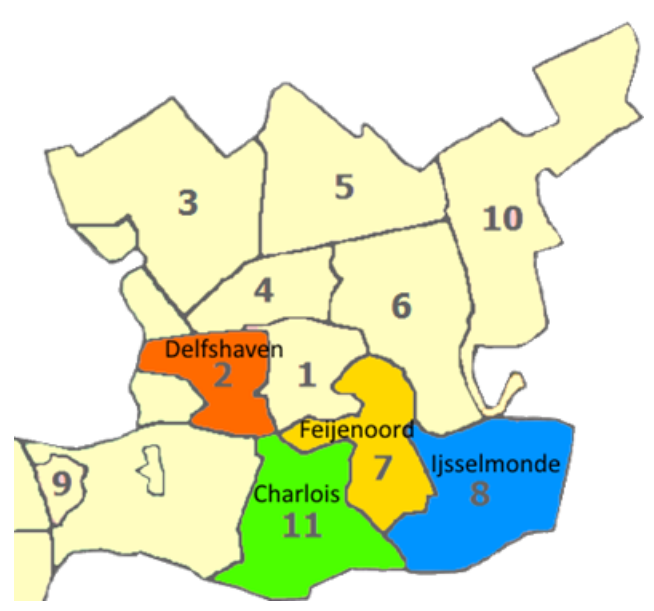

Figure 2. Rotterdam divided into city districts, highlighted no. 2, no. 7, no.8 and no. 11. Source: Author.

\footnotetext{
${ }^{1}$ The definition of the intersectionality theory (is it a theory? Is it a methodological framework or a heuristic paradigm?) is the object of an ongoing interesting and articulated debate, which cannot be accounted for here, so I refer to Bello (2015) and Marchetti (2013) for an in-depth analysis of it.
} 
lens for investigating multiple intersecting discriminations, considering them a process in which the resulting discrimination cannot be taken for granted as a mere sum of the original discriminations in that it becomes a sui generis phenomenon, with new and peculiar characteristics (McCall, 2001). In this work, I use the insights provided by this approach pragmatically to frame the research on two levels. The first one is the profiling of the interviewees, which was conducted considering the complexity of the intersection of different personal characteristics. The second level concerns the analysis of the specific intersections between the abovementioned personal characteristics and the contextual spatial categories of spatial position, spatial acknowledgement, and spatial mobility. These categories were identified starting from the definition of space provided by Massey (1984), who described it as constituted by distance, place, symbolism, and movement. These elements can be easily reconducted to the above-mentioned categories, in which distance refers to the position of people and objects within the city, place and symbolism are associated with the symbolical dimension of the acknowledgement and sense of belonging, and movement is connected to the mobility within an urban space.

Therefore, the heterogeneity of the two groups of interviewees depends not only on their characteristics taken as per se entities, but also on the specific intersection of personal and spatial categories which entail peculiar positions within society and different degrees of participation, appropriation of space, and sense of belonging.

\section{Spaces of Representation in Milan and Rotterdam}

\subsection{Milan: A Neighbourhood School as a Space of Representation}

\subsubsection{The Place and the People}

The sample coming from Milan concerns a neighbourhood school, hosting children from 3 to 14 years old, in one of the focal areas of the research.

The most important characteristic of the school is its position within a park, which during school hours is completely devoted to pupils: When children are at school, no one but school staff can enter the park. Usually children play in the park after school, and adults create relationships with other parents (or child carers in general).

The second peculiar aspect of the school is the social composition of pupils attending it. Indeed, the school hosts a very high number of students who have an immigrant background, and the educational and social environment is strongly multicultural. This is because the school is located in a highly diversified neighbourhood, in which the share of foreign minors is close to $50 \%$ (Comune di Milano, 2015).

The third element to take into consideration is the presence of a civil association in the park. This is very much bonded to the context because the association implements activities targeting children and adults within and outside the park. The association's main aim is the improvement of the park and the social participation of its regulars, but the activities implemented usually try to involve the entire neighbourhood (even if with limited results).

The group of people who make it a representational space is constituted by people who generally have children or who take care of them (for kinship bonds or professional reasons). They are mostly Italians or long-term resident foreigners with high social skills and excellent proficiency in the Italian language. In this group, the female component is neatly predominant with respect to the male one. This can be linked to the unbalance in the sharing of childcare responsibilities between women and men within the family, which is relevant also in the practices and activities connected to the school (Barker, 2011), and it generally couples with the limited mobility experienced, or at least perceived, by the interviewed attendees. For simplicity, I will call this group the child carers group.

\subsubsection{Participation, Sense of Belonging, and Appropriation: A Gendered Representational Space}

The first thing to say to introduce myself is that I am a mother of two daughters....And then, an important piece of my life is the fact that I live here....Because of the neighbourhood-and above all the neighbourhood school-[name of the place] is a place of encounters, of friendships, and of engagement. It's the place where my daughters spend most of their time, so I created a net of friends there, and it became the most important for me. And so, this thing had to be underlined to explain who I am. (M10)

As clearly stated in the quotation above, the predominance of mothers and (female) child carers within this group is at the basis of an identification process that implicitly excludes part of the feminine population (women without children) and almost the entirety of the masculine one. Consequently, the place assumes a peculiar gendered dimension which strongly influences the way in which the dynamics of participation and belonging take place. Participation is, indeed, basically linked to children's activities and mothering practices, and these practices ground a strong sense of community and belonging: It's primarily through the mutual help in childminding, for example, that intragroup solidarity takes place. This very strict gendered and parental space's connotation results in a sort of appropriation of it by the child carers' group which links its identity with the place-identity:

I define it [the school and the park] as a little welcoming community. I feel at home here. (M1)

You get to know other moms here, and you become friends. And when you understand that your prob- 
lems are the same as their problems, you start to create some 'survival strategies'. We help each other with children. I know that there are some women who play the role of 'fake grannies' to help some moms with their children. (M12)

Nevertheless, the emergence of the representational space is also linked to specific socio-spatial features that come into play and that intertwine with the gendered and parental dimension. In this case, a strong role is played by the position of the school within the park:

And the park constitutes a proper 'lung' for the area, not only in terms of trees and clean air, but also in terms of sociality and spaces. Spaces that are devoted to children but also to adults. (M17)

The limited mobility of the child carers' group is one of the motivations encouraging mothers to attend the park regularly: In this way, they manage to balance part of their family workload with socialization and groupidentification needs. However, their strong emotional bond with place and people is long lasting. Even when the children grow older and leave the school, the child carers' group continues to attend the park and the school, even if with different roles-above all, as volunteers for the association.

This process may be seen as a socially virtuous circle: Support is provided when needed, and at the same time, women are empowered and stimulated to engage and volunteer, in turn supporting other women in need (even if this support network is provided exclusively to insiders).

Insiders perceive the park as a familiar place that they usually describe as being like home. This is due to the commitment within this little community, the strong sense of belonging, and the identification processes that take place within the park. This thick group unconsciously creates high barriers to the access that fosters the perception of a safe and domestic environment. These characteristics, in addition to their link to the mothering practice, make this place a hybrid space between the public and private spheres, where the latter seems to pervade the former through a partial appropriation of it.

This process results in a representational space which is created through the gendered redefinition of meanings, narratives, and practices that connote it as an emotional place-based dimension.

With this term, I intend a representational space in which mainstream and dominant perceptions and conceptions of the space, as well as the power relations lying on it, are renegotiated by way of an emotional involvement with the place in a recursive process. In the case of the neighbourhood school, the renegotiation concerned the gendered redefinition of the separation between the public and domestic spheres, with a trespassing of one into the other. In this sense, an opposite example may be what Del Re (2016) called a multifunctional-island house (casa isola polifunzionale). With this expression, Del Re referred to the increasingly different forms of work-fromhome, which cause an intrusion of the public sphere into the private one. Different from the case presented here, the multifunctional-island house fosters isolation, frustration, and a negative emotional response to the place.

However, the representational space of the park has negative side effects, too. If the strong community bond engenders a support network for insiders, it also generates exclusion and high access barriers for outsiders. This is not only negative for outsiders, but also for the same group, which risks being too closed off and finding itself surrounded by an unfriendly environment:

This thing drives me mad! I can't stand that we can't use the park for the entire morning and part of the afternoon because all turns around kids! I live this thing as a discrimination: I can't live that place because I don't have children. And I think it's foolish because that place is such a wonderful place where a lot of initiatives could be implemented for all, not just for a part of the neighbourhood. (M6)

The second dark side of this representational space is in the same hybrid nature between a public and a private space: Although it has undeniable effects of improving women's lives, mixing childminding responsibilities and social needs can actually worsen the unbalance of the workload within the family and strengthen the stereotypical role division through the implicit exclusion of men from this space. This may result in a weakening of women's agency and advocacy power as citizens.

\subsection{Rotterdam: A Community Garden as a Representational Space}

\subsubsection{The Place and the People}

The example emerging from Rotterdam concerns a community garden located in one of the most deprived areas of Rotterdam South. Actually, this community garden does not exist any longer. Indeed, a few weeks after my research campaign finished, it was closed following a decision of the municipal council that has been described by the local press as schizophrenic (see for example, Loorbach \& van Steenbergen, 2015).

During the fieldwork, the death sentence for the garden had already been emanated, and much of the concern expressed by the interviewees was directed to the upcoming closure. An adjacent school was going to buy the fertile garden to expand its facilities and build a parking area for its staff. However, the tensions and the extensive debate that took place around this community garden and the fact that eventually it was closed prove the relevance that this space had gained and make it particularly interesting in this work perspective.

The community garden aimed to improve neighbourhood life thanks to the shared and delightful use of green 
areas and their productive capacity. The garden was run by a foundation that utilized volunteers. At first, the garden was subsidized by the municipality, and at the same time, its sustainability was granted by the exchange between products (the garden hosted various kinds of crops, from flowers to vegetables) and in-kind contributions. Cash contributions were discouraged because the organisers wanted the initiative to be a social and not economic venture.

Volunteers organised themselves through shifts as necessary to keep the garden open at least some days each week. Nevertheless, anyone who wanted to enter and collaborate was welcome at any time. A couple paid persons oversaw management and organisational tasks, including various projects that were implemented within the garden.

Notwithstanding its open access, the garden was mostly attended by a specific group of people comprised of low-income Dutch natives, usually over 45 years old. The most characterising element of the group attending the garden was that most of these people had gone or were going through troubled periods in their lives, connected to socioeconomic or health issues (e.g., the loss of their job, an addiction, illness, and the like).

Although activities implemented within the garden were not significantly gendered, nor was the place determined to be particularly women-friendly, most of the attendants/volunteers were women from 45 to 60 years old. This could be associated to the above-mentioned peculiarity of being a place where people with troubled personal histories find room: Women are generally more exposed to socioeconomic vulnerability, having a weaker position within the labour market (Hegewisch \& Hartmann, 2014).

\subsubsection{Participation, Sense of Belonging, and}

Appropriation: The Value of Being Active

This is also my city, that's why I want to have this garden, this space. Here in the garden everyone is worthwhile as a person, not like somebody who can buy things, but somebody who can do things, and by doing things can be part of the society, and being part of this society, can be responsible, responsible together. And this I think is the most amazing thing that can happen in places like this, it doesn't happen in shopping malls. (R27)

The quotation above highlights how the chance to participate into a productive activity which gave volunteers the perception of creating something new and beautiful in a deprived context made the community garden a representational space. Adding value to the place was the fact that these people managed to feel themselves worthy and useful in this society.

Most of the people attending the garden, due to their vulnerable socioeconomic positions, had experienced a sort of expulsion from city life, which resulted in a perceived spatial expulsion from most urban spaces in Rotterdam. Places and infrastructures that they attended before suddenly became somehow inaccessible and not welcoming. The perception of being excluded from their city was mirrored in their difficulty finding a (localized) source of identification and belonging. The following quotation from an interviewee, although quite long, is worth being fully included for its completeness and clarity:

And what happens when you lose a job? What happens is that you get sort of cut off of most of the things that are going on in the city....So it's like you have to reinvent the city for yourself because there are so many places, there are so many...not so much closed off, is that you're not able to do anything there. It was really difficult to me in the beginning to feel safe and to feel that there was a place where you can belong, and then I came here at the garden, and I walked in, and I said, 'Do you need a volunteer?' And they said, 'Yes, sure!' And within the year I realized that I had found what I was looking for, a place where I didn't have to pay anything, where I was welcomed, where I can make a difference, where I can do something, and where I'm again part of a small community. So, this garden has been a life saver to me. (R27)

The community garden helped these people to establish new, acknowledged, and worthy identities and to belong to a place even if they were not able to economically contribute to city life in a different manner: Their economic and personal values were decoupled.

This engendered a sense of attachment and belonging to the place, the perception of being in a safe and familiar environment where all could express themselves through participation, bringing their personal value to the community.

People from very different backgrounds formed strong interpersonal bonds and a sense of belonging to the place-based community, linking their participation to a green culture, a kind of common value:

I always liked nature and peace and green surroundings, but now I realize more than ever how important is a piece of land, with trees and the possibility to let vegetables grow, how important it is for people who haven't a garden and are longing for being outside. So, yeah, my ideal of how important social life and green surrounding, how important it is for a lot of people is growing; my awareness is growing more than ever. (R25)

In this respect, the community garden is a place that generates a significant emotional involvement by means of activities such as farming and gardening in the first place but also by providing new identities to the volunteers. The narrative of personal rebirth is much shared among the attendees and is reinforced by the personal responsi- 
bility in the 'rebirth' of the garden's natural environment and in the general improvement of the neighbourhood, too: The area is perceived as highly stigmatised (stigmatisation which, according to interviewees, is only partly justified by its actual conditions).

As already seen in regard to the neighbourhood school in Milan, the community garden generates an emotional place-based dimension where feelings of attachment and active participation come into play to redefine power relations, laying into the mainstream perceptions and conceptions of the space.

In this case, the renegotiation does not directly involve a gendered dimension, but it is focused on the value of the individuals against the loss of economic capability due to different contingencies during their life course. In that space, people can feel accepted again and appreciated according to a 'decommodified' value system. Vulnerable people were able to find a place and renegotiate their own social value by way of an alternative conception of a space where economic rules are bracketed.

The appropriation of this space occurred through its improvement and through the emotional investment that volunteers put into that activity. The familiar environment and the community dynamics taking place in the garden blurred the boundaries between the domestic and the public spheres. Most of the volunteers barely distinguished the two spheres of life, increasingly investing in terms of emotional commitment to the place.

As in the case of the neighbourhood school in Milan, one of the consequences of this trespassing of the domestic sphere into the public one is that on the one hand, it engenders a warm and welcoming environment for insiders who manage to find support networks within the group. On the other hand, in-group bounded solidarity creates high access barriers for outsiders who, in particular cases, do not manage to gain access. In the case of the community garden, radical exclusion prevalently regarded immigrants with limited proficiency in the Dutch language. Furthermore, most of the volunteers went through a long process before feeling accepted and welcomed within the garden. This bounded solidarity may have a sort of lock-in effect which limits insiders' capacity to create wide and transversal social networks that may help them to face daily problems.

The garden was closed in December 2015 for more profitable uses of the land. This was consistent with the urban renewal plans of the administration, which aimed to make the city, and especially its more deprived neighbourhoods, more economically attractive. When the closure was announced, the volunteers responded by increasing their attachment to the place. Their response, however, did not prove sufficient to prevent the closure of the garden and the resulting loss of years of voluntary and community work.

In this sense, one of the main weaknesses of the community garden was its complete dependency on public financial support. Although most of the people involved in the gardening and farming were volunteers who worked for free, the entire management and the foundation who ran the garden had costs that could not be covered by the municipality: The garden was basically a social place that needed to expel profit-driven logics from itself to stay a 'social' place of its kind. Therefore, when the City Council made the decision to close the garden, the funding was stopped and the people who had literally constructed the place had no advocacy power to oppose that decision.

\section{Spaces of Urban Citizenship in Milan and Rotterdam}

The representational spaces presented above set the basis for the emergence of alternative forms of urban citizenship within the two cities, which takes place through a spatialised performance of the right to the city. But how does this happen? It occurs by means of participation in a social network and its activities which delineates an explicit or not appropriation of a specific space and engenders a sense of belonging to that (physical and symbolic) space.

Starting again with Milan, the neighbourhood school context fosters the emergence of a form of urban citizenship characterised by two basic aspects: It is childcentred and space-specific. The expression child-centred refers to the pivotal role played by the parental practice in defining the place-identity, which in turn influences the way in which affiliation and feelings of attachment are constructed: The school network provides a strong sense of belonging which is based on the self-definition of and identification with the role of 'mother.' This role becomes the access key to the community, and it is a source of self-identification and hetero categorization which allows people in this group to feel part of a clearly defined community. The strong sense of belonging supports a strongly bounded solidarity. The appropriation of the spaces of the school and the park takes place through these practices, which are emotionally characterised and require a certain degree of personal involvement. As a consequence, those not fitting into the strict characteristics of the group are excluded.

The result of this kind of associative and appropriative practices is a sort of micro-citizenship based on childcare practices and connected to the physical and symbolic space of the park (and that for this reason has been defined as space-specific).

On the one hand, this kind of citizenship can be considered a representational citizenship, a symbolic space where women within the neighbourhood manage to express themselves and give positive value to their caregiving roles. On closer inspection, though, this kind of participative practice is based on women's factual limitation in mobility and in their limited access to active and political urban spaces.

Therefore, the strong gendered characterisation of this model of urban citizenship is related to the imbalanced sharing of family workload within the domestic sphere that also permeates the public sphere. If the over- 
load of care-work for women becomes a participative and integrative device in this little community, these same practices are confined within the park and the associative activities, limiting women's political and social influence in other urban spaces.

The result is the creation of a hybrid dimension of urban citizenship which is confined within a specific space and linked to parental practice and that worsens rather than improves women's opportunities for participation at the city level. Indeed, access to this form of urban citizenship seems to be an adaptive strategy which, at most, enables women to insert themselves in interstitial urban spaces.

Women's agency seems to be in this way confined within a semi-domestic urban space, where boundaries among private and public sphere are blurred and where gendered stereotypes are strengthened rather than challenged.

In Rotterdam, the economic capability of inhabitants seems to play a central role in defining their spaces of urban citizenship and in grounding alternative, or even insurgent, forms of urban citizenship.

Even in this case it is possible to argue that the representational space created within the community garden engenders a peculiar kind of urban citizenship by means of the practices, relationships, and affiliation bonds.

Different from the Milanese case, the community garden is not based on gendered practices or stereotyped gender roles. Nonetheless, this representational space sees a prevalence of women, which connotes in a meaningful way the place-identity.

As argued, the accentuated socioeconomic vulnerability of women makes them the most subjected to the loss of access to mainstream urban spaces and at the same time, makes them the most inclined to participate and activate for the creation of a space which can stand outside market logics and mechanisms.

People in this garden made an effort to rescue a social and physical space from the strict market logics which rule in an increasingly pervasive way the definition of urban space and urban citizenship in Rotterdam (see Uitermark, Duyvendak, \& Kleinhans, 2007). The garden's volunteers managed to define an alternative way to enjoy and participate in city life through the appropriation of that space. Its management was focused on the human value of the individual rather than on his/her economic capability, and this generated a sense of attachment and belonging to the place.

Through the emotional bond that they created within this space, the volunteers managed to feel part of a community, and they overcame the sense of exclusion from the city that they had previously perceived. They explicitly addressed their affiliation to the garden as a way to regain their urban citizenship and the dignity of their status as Rotterdammers.

On the one hand, this was an important success of this initiative, which helped marginalised and vulnerable people feel useful and provided access to the right to the city from which they had been expelled. They managed to redefine and renegotiate the meaning of participation (voluntary activities), modalities of appropriation (exchange without economic obligations), and the value of the sense of belonging (not based on economic conditions).

On the other hand, this kind of access to and appropriation of urban citizenship rights can be seen as a failed attempt to get out of a sphere of political invisibility. Indeed, this kind of alternative urban citizenship is based on an adaptive strategy aimed at overcoming the limitations caused by their expulsion from the remunerative, productive sphere. In a moment of vulnerability, these people found themselves deprived of advocacy power and, finally, excluded from most of the urban spaces and initiatives going on in their city.

By finding room for their social and urban citizenship rights within the community garden, the people involved gained a sort of containment of their potential political role that had disqualified them as urban citizens. Furthermore, the fulfilment of their needs for participation and for belonging to a community, through a partial and revocable appropriation of that kind of urban space, ended up reinforcing the basic subdivision between the domestic and public spheres rather than challenging it.

Indeed, as for the neighbourhood school and park in Milan, the community garden resulted in being a hybrid space between the public and domestic spheres, where activities and practices of participation are based on and nurtured through high emotional involvement that produces strong affiliation bonds. At the same time, though, this kind of space raises high access barriers and reduces the advocacy and political power of the people who live those bonds as insiders.

In this sense, the closure of the garden is evidence of the weakness of this group, and it marks in a significant way the direction that the local government wants the city to follow. Frustrating all of the attempts to save the garden and all of the requests of the foundation and volunteers to be listened to, the city did not just make a contingent decision, but they decided on a specific overall direction for the city. People living the garden have perceived the decision taken by the administration as a further clear message about what a Rotterdammer should be, or better, what a Rotterdammer should have to be considered a worthy urban citizen, and they do not mirror themselves in that definition.

\section{Conclusions: Representational Spaces as a Double-Edged Sword?}

The examples of representational space in the two cities give me the opportunity to draw some conclusions about the trajectories that urban citizenship can take depending on the peculiar intersection of context-based factors. As the examples have shown, the two considered places seem to foster the performance of the right to the city and the emergence of urban citizenship in different ways: In Milan, the main role is played by gendered roles and 
practices which express themselves in mothering and childminding activities, and in Rotterdam, the basic element is the contraposition to market-driven logics by the means of green and social activities.

On closer inspection, though, some common points between the two cases emerge, and they seem to be connected to the same main drift along which practices and identification processes take place.

In particular, some features coming from the common industrial past of the two cities prove to be relevant: the neat physical and symbolic separation between the public and domestic spheres and between the productive and reproductive realms, within which the role of women is still clearly and definitely connected to the second, subaltern, emotional, and marginal sphere of domesticity.

As a matter of fact, in both cases, women try to escape from this marginal condition via adaptive strategies, accessing and appropriating interstitial urban spaces. These spaces are interstitial because they are left behind by the, so to speak, 'dominant citizens,' and they assume a gendered meaning which makes them appear as hybrid spaces, emotionally connoted, in a grey zone between the private and public life. Although in Milan the gendered dimension of this cleavage is much more perceived as such, in that it is also explicitly addressed in spatial practices, this dimension is not less important in Rotterdam. In this case, it is disguised through neutrally perceived practices, but it is still pivotal in determining the conditions of socioeconomic vulnerability. Vulnerability and marginality, in turn, determine the expulsion from certain spaces and from the dominant modalities of urban citizenship, which consequently fosters a search for alternative ones.

The intersection between space and gender seems to confine vulnerable people into a specific emotional place-based dimension. Indeed, albeit significantly important for self-definition and for overcoming conditions of isolation, these forms of urban citizenship have a disqualifying effect on the advocacy power of vulnerable citizens, because they are not able to empower those citizens in a social and political way. This is because of the peculiar socio-spatial configuration in which they are embedded: The domestic sphere invades the public one, reproducing, in fact, a private dimension in a public space. These dynamics do not break the stereotypical male/female division (as emerges from the Milanese case), and they do not challenge the subaltern position of women and other vulnerable categories in the market-driven society (as the Rotterdam case shows). They can provide relief and satisfaction, (partially) neutralising possible conflicts between these groups and the rest of the city. The advocacy power of these groups is, in this way, weakened by a lower motivation to participate in the wider context of the city (which still is the real political space) and by the fact that being lived and perceived as a private dimension, these spaces do not have any public or political weight, and these groups are not able to influence or even be listened to at the political and administrative levels.

However, this does not make the emergence of these representational spaces less positive. The challenge for urban level policy makers is exactly in taking advantage of these bottom-up processes, fostering the positive effects that they have (such as the creation of community and solidarity bonds, the sense of belonging and attachment to the place, and the ability to overcome more or less severe forms of isolation with the consequent possibility to access vulnerable groups) and limiting their negative side effects with dedicated measures and activities aimed at empowering these places and groups. Though in Milan this has been difficultly done so far by the above-mentioned civil association, in Rotterdam, the lack of public support determined the closure of the garden and the loss of years of work and of a slowly rising social capital.

Therefore, urban spaces are far from being neutral in a wider and more pervasive sense than just in relation to the typical gender-related issues of security and the work-family balance. At issue is the same possibility to self-determine and self-define oneself as an urban citizen and have access to the right to city.

\section{Acknowledgments}

This work was supported by the European Union's Seventh Framework Programme for research, technological development and demonstration under Grant Agreement no. 319970-DIVERCITIES. The views expressed in this article are the sole responsibility of the author and do not necessarily reflect the views of the European Commission. The publication has been funded by the Department of Economics, Society and Politics of the University of Urbino Carlo Bo, Italy.

\section{Conflict of Interests}

The author declares no conflict of interests.

\section{References}

Angelucci, A., Marzorati, R., \& Barberis, E. (2019). The (mis)recognition of diversity in Italy between policy and practice: The case of Milan. European Urban and Regional Studies, 26(3), 254-267.

Barberis, E. (2018). Interculturalism as conservative multiculturalism? In S. Oosterlynck, G. Verschraegen, \& R. van Kempen (Eds.), Divercities: Understanding super diversity in deprived and mixed neighbourhoods (pp. 113-138). Bristol: Policy Press.

Barberis, E., Kazepov, Y., \& Angelucci, A. (2014). Assessment of urban policies in Milan, Italy. Urbino: DESPUniversity of Urbino Carlo Bo.

Barker, J. (2011). "Manic mums" and "distant dads"? Gendered geographies of care and the journey to school. Health and Place, 17(2), 413-421. 
Beauregard, R. A., \& Bounds, A. (2000). Urban citizenship. In E. F. Isin (Ed.), Democracy, citizenship, and the global city (pp. 243-256). New York, NY: Routledge.

Bello, B. G. (2015). Diritto e genere visti dal margine: Spunti per un dibattito sull'approccio intersezionale al diritto antidiscriminatorio in Italia [Rights and gender seen from the margins: Ideas for a debate on the intersectional approach to anti-discrimination law in Italy], Diritto e Questioni Pubbliche, 15(2), 141-171.

Chiodelli, F. (2009). La cittadinanza secondo Henri Lefebvre: Urbana, attiva, a matrice spaziale [Citizenship according to Henry Lefebvre: Urban, active, with a spatial matrix]. Territorio, 51(4), 103-109.

Comune di Milano. (2015). Sistema Statistico Integrato. Retrieved from sisi.comune.milano.it

Crenshaw, K. (1989). Demarginalizing the intersection of race and sex: A black feminist critique of antidiscrimination doctrine, feminist theory and antiracist politics. University of Chicago Legal Forum, 1989(1), 139-167.

Del Re, A. (2016, May 26). II lavoro cambia le città [Work changes cities]. inGenere. Retrieved from http:// www.ingenere.it/articoli/il-lavoro-cambia-le-citta

Duyvendak, J. W., \& Scholten, P. (2012). Deconstructing the Dutch multicultural model: A frame perspective on Dutch immigrant integration policymaking. Comparative European Politics, 10(3), 266-282.

Eurostat. (2014). Population change: Demographic balance and crude rates at regional level (NUTS 3). Eurostat. Retrieved from http://appsso.eurostat. ec.europa.eu/nui/show.do?dataset=demo_r_gind3\& lang=en

Fairclough, N. (2003). Discourse analysis. London: Routledge.

Fenster, T. (2005). The right to the gendered city: Different formations of belonging in everyday life. Journal of Gender Studies, 14(3), 217-231.

Glick Schiller, N., \& Çağlar, A. (2010). Locating migration: Rescaling cities and migrants. Ithaca, NY: Cornell University Press.

Glick Schiller, N., \& Çaglar, A. (2015). Displacement, emplacement, and migrant newcomers: Rethinking urban sociabilities within multiscalar power, Identities, 23(1), 17-34.

Harvey, D. (2008). The right to the city. New Left Review, $53,23-40$.

Hegewisch, A., \& Hartmann, H. (2014). Occupational segregation and the gender wage gap: $A$ job half done. Washington, DC: Institute for Women's Policy Research.
Holston, J. (2008) Insurgent citizenship: Disjunctions of democracy and modernity in Brazil. Princeton, NJ: Princeton University Press.

Koopmans, R. (2013). Multiculturalism and immigration: A contested field in cross-national comparison. Annual Review of Sociology, 39, 147-169.

Lefebvre, H. (1968). Le droit à la ville [The right to the city]. Paris: Édition Anthropos.

Lefebvre, H. (1974). La production de l'espace [The production of space]. Paris: Édition Anthropos.

Loorbach, D., \& van Steenbergen, F. (2015, 26 June). Carnissetuin tegen de vlakte voor groen wonen [Carnissetuin against the plain for green living]. Vers $\mathrm{Be}$ ton. Retrieved from https://versbeton.nl/2015/06/ carnissetuin-tegen-de-vlakte-voor-groen-wonen

Marchetti, S. (2013). Intersezionalità [Intersectionality]. In C. Botti (Ed.), Le etiche della diversità culturale [Ethics of cultural diversity] (pp. 133-148). Florence: Le Lettere.

Massey, D. (1984). Introduction: Geography matters. In D. Massey \& J. Allen (Eds.), Geography matters! A reader (pp. 1-12). Cambridge: Cambridge University Press in Association with the Open University.

McCall, L. (2001). Complex inequality: Gender, class and race in the new economy. New York, NY: Routledge.

Painter, J. (2005). Urban citizenship and rights to the city (Background Paper for the Office of the Deputy Prime Minister). Durham: International Centre for Regional Regeneration and Development Studies (ICRRDS), Durham University.

Pine, A. (2010). The performativity of urban citizenship. Environment and Planning A, 42(5), 1103-1120.

Plyushteva, A. (2009). The right to the city and struggles over urban citizenship: Exploring the links. Amsterdam Social Science, 1(3), 81-97.

Purcell, M. (2002). Excavating Lefebvre: The right to the city and its urban politics of the inhabitant. GeoJournal, 58(2/3), 99-108.

Purcell, M. (2003). Citizenship and the right to the global city: Reimagining the capitalist world order. International Journal of Urban and Regional Research, 27(3), 564-590.

Tersteeg, A. K., van Kempen, R., \& Bolt, G. S. (2013). Urban policies on diversity in Rotterdam, the Netherlands. Utrecht: Faculty of Geosciences of Utrecht University.

Uitermark, J., Duyvendak, J. W., \& Kleinhans, R. (2007). Gentrification as a governmental strategy: Social control and social cohesion in Hoogvliet, Rotterdam. Environment and Planning A, 39(1), 125-141.

\section{About the Author}

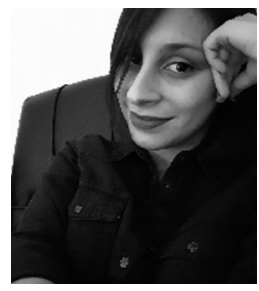

Alba Angelucci (b. 1988) holds a PhD in Sociology, Governance, Social Participation, and Citizenship. She is a Research Fellow in Sociology and Adjunct Professor of Gender and Family Sociology at the Department of Economics, Society and Politics at the University of Urbino Carlo Bo, Italy. Her main research interests concern discrimination and inequality dynamics, mainly analysed through an intersectional perspective which considers gender and origin-related disadvantages. 